\title{
Análise Climática da Bacia Hidrográfica do Rio Ipojuca-PE
}

\section{Climate Analysis of The Ipojuca-PE Rio Hydrographic Basin}

\author{
Raimundo Mainar de Medeiros ${ }^{1}$
}

Universidade Federal Rural de Pernambuco - UFRPE ${ }^{1}$

mainarmedeiros@gmail.com

DOI: https://doi.org/10.52719/bjas.v2i1.3087

\section{RESUMO}

O estudo conduzido em como objetivo o diagnóstico do clima e das disponibilidades dos recursos hídricos da bacia hidrográfica do rio Ipojuca e seu entorno. Na caracterização climática utilizou-se os dados de precipitação, temperatura máxima, média, mínima, amplitude térmica, umidade relativa do ar e insolação total. Os elementos climáticos evaporação e evapotranspiração foram determinados pelo método do cálculo do balanço hídrico segundo Thornthwaite e Mather (1955). As análises dos procedimentos das distribuições dos elementos acima referenciados foram aplicadas aos meses e entre anos para os 25 municípios da área de entorno em estudo, para a série dos dados de 1962-2018. As temperaturas foram estimadas pelo método de regressão linear múltipla, geradas pelo software Estima_T. Os aspectos físicos e as características do uso do solo podem influenciar a distribuição das temperaturas, sendo que locais densamente construídos e desprovidos de vegetação apresentaram temperaturas maiores, enquanto que os locais com maior taxa de arborização, menores taxas de construções registrouse temperaturas reduzidas. Os municípios de entorno da área em estudo necessitam desenvolver-se pautados em planejamento urbano eficiente e que venham a suportar fenômenos naturais de maior magnitude. Os ambientes instáveis da cidade não deveriam ser ocupados por construções e nem ter sua dinâmica natural alterada.

Palavras-chave: Balanço hídrico. Flutuações climatológica. Impacto. 


\section{ABSTRACT}

The study was carried out with the objective of diagnosis of the climate and the availability of water resources in and around the Ipojuca river basin. In the climatic characterization was based on rainfall, maximum, average, minimum and thermal temperature, relative humidity, total insolation, evaporation and evapotranspiration climatic elements were determined by the water balance calculation method according to Thornthwaite and Mather. The analysis of the distribution procedures of the elements referred to above were applied months and years to the 25 municipalities in the surrounding area under study, for the 1962-2018 data series. The temperatures were estimated by the multiple linear regression method, generated by the Estima_T software. Physical aspects and land use characteristics can influence the temperature distribution, with densely built and vegetation-free sites showing higher temperatures, while sites with higher afforestation rate, lower construction rates showed reduced temperatures. The municipalities surrounding the area under study need to develop based on efficient urban planning that can support natural phenomena of greater magnitude. The unstable environments of the city should not be occupied by buildings nor have their natural dynamics altered.

Keywords: Water balance. Climatological fluctuations. Impact.

\section{INTRODUÇÃO}

Nas últimas décadas pesquisadores e a comunidade científica vêm demonstrando interesse na aplicabilidade dos dados climáticos sobre o ponto de vista pleno e de suas oscilações espaciais e temporais, resultante da conscientização de que o ser humano influencia as camadas da atmosfera, o que vem contribuindo com o aquecimento global e com os impactos na camada de ozônio, que está situada sobre as regiões polares e suas adjacências.

Os monitoramentos do clima, primeiramente voltados para a previsão do tempo, meteorológico e zoneamento agroclimático passaram recentemente a incorporar os temas ligados às mudanças climáticas, eventos extremos, propendendo ao entendimento do sistema terrestre. Estudos sobre os procedimentos das variáveis climáticas locais, regionais e globais trazem contribuições importantes, já que as atividades antrópicas vêm modificando o ambiente, resultando em notáveis alterações no fluxo de energia, dentro do sistema climático regional ou local, mas com reflexos globais (Barrett \& Curtis, 1992). O monitoramento da precipitação é 
uma ferramenta indispensável na mitigação dos efeitos das secas, cheias, enchentes, inundações, desmoronamento e alagamentos (Paula, Brito, \& Braga, 2010).

Simoni, Rovani, Zensse e Wollmann (2014) mostraram que a análise da distribuição pluvial em bacia hidrográfica é um mecanismo relevante para nortear medidas para o uso racional dos recursos hídricos. Deste modo, a compreensão dos regimes pluviais torna-se um artifício para elaboração de planejamentos socioeconômicos e da conservação ambiental.

Os elementos temperatura média do ar, precipitação, umidade relativa do ar, evaporação, evapotranspiração, insolação estão diretamente relacionados à agricultura, por sua importância junto aos processos climáticos, os quais são alvo de pesquisas. São os elementos meteorológicos que exercem influência direta sobre as condições agrícolas (Amorim, Amorim, Leite, \& Gomes, 2004). O desenvolvimento da agricultura e o início da revolução industrial levaram a um explosivo crescimento populacional, que, por sua vez, pressionou os recursos naturais do planeta (Artaxo, 2014). Segundo o autor, estudos sobre os recursos hídricos, características hidrológicas, climatológicas, agroecológicas e agroclimáticas, topografia, declividade do terreno, solos e cobertura vegetal são fundamentais para um bom planejamento socioeconômico e agrícola regional.

Monteiro (2000) mostrou que o crescimento populacional e da atividade industrial conduzem a uma demanda cada vez maior por energia. A escassez dos recursos naturais e a crescente agressão ao meio ambiente para suprir tal demanda vêm sendo apontadas como fatores de desequilíbrio ao ecossistema. Incluindo em vista tal situação, a utilização de energias não convencionais tem sido apontada como uma solução alternativa ao modelo energético em vigor.

Magalhães, Zanella e Sales (2009) demonstraram que os rios com suas águas poluídas e/ou contaminadas constituem-se em foco de disseminação de doenças veiculadas por meio hídrico. Exemplo disso é a leptospirose, que apresenta maior concentração de casos nos meses chuvosos, cuja população entra em contato com a água de rios e das inundações que extravasam o seu leito.

Silva, Pereira, Azevedo, Souza e Sousa (2011) mostraram que a compreensão do regime de chuva em determinada região é um indicador para constituição de calendário e implementação de projetos agrícola.

Souza, Silva e Ceballos (2008) mostraram que a componente mais importante a influenciar processos atmosféricos e as condições do tempo e clima no planeta Terra é a energia 
proveniente do Sol, responsável pelo aquecimento do ar e do solo, fotossíntese e evaporação da água. As variações no saldo de radiação são fundamentais nos processos atmosféricos e terrestres alterando, por exemplo, a temperatura na superfície, o perfil da taxa vertical de aquecimento e a circulação atmosférica.

Klering, Custódio, Fontana e Berlato (2007) mostraram que a duração do brilho solar pode ser de grande importância em atividades agrícolas. Por exemplo, ela tem relação estreita com o Índice de Vegetação por Diferença Normalizada (NDVI) de arroz irrigado e, por conseguinte, correlação elevada com o rendimento da cultura.

Na região Nordeste do Brasil (NEB), em especial na região semiárida nordestina onde se encontra alocada a bacia hidrográfica do rio Ipojuca, é que frequentemente afronta problemas de seca e estiagens prolongadas dentro do período chuvoso, enchentes, inundações, alagamentos e eventos extremos, estas condições se tornam ainda mais graves (Nobre \& Melo 2001). Horikoshi e Fisch (2007) afirmam que recentemente é enorme a demanda pelo uso dos recursos hídricos, sendo o seu conhecimento importante para realizar o monitoramento do ciclo da água, principalmente das variáveis climáticas, precipitação evapotranspiração, evaporação, umidade relativa do ar.

Camargo (1971); Horikoshi e Fisch (2007) afirmaram que para se ter o conhecimento de dada região a qual exibe deficiência ou excesso de água durantes os anos, é necessário comparar dois termos contrários do balanço, a precipitação (responsável pela umidade do solo) e a evapotranspiração, que utiliza essa umidade do solo. Segundo Pereira, Angelocci e Sentelhas (2002); Horikoshi e Fisch (2007) a água disponível para o consumo e uso do ser humano pode ser quantificada pelo BHC, ficando evidente a variação temporal de períodos com excedente e/ou com deficiência hídricas, permitindo, dessa forma, o planejamento agropecuário. $\mathrm{O}$ balanço hídrico como unidade de gerenciamento permite classificar o clima de dada região, realizar o zoneamento agroclimático e ambiental, determinar o período de disponibilidade e necessidade hídrica no solo, além de favorecer ao gerenciamento integrado dos recursos hídricos e também a viabilidade de implantação e monitoramento de sistemas de irrigação ou drenagem numa região (Lima \& Santos, 2009).

O presente trabalho tem como objetivo estudar e analisar os elementos do clima e das disponibilidades dos recursos hídricos superficiais e subterrâneos da bacia hidrográfica do rio Ipojuca e seu entorno, com o intuito de gerar informações aos tomadores de decisões governamentais. 


\section{MATERIAL E MÉTODOS}

A bacia do rio Ipojuca (BHRI) localiza-se em sua totalidade no Estado de Pernambuco, entre $08^{\circ} 09^{\prime} 50^{\prime \prime}$ e $08^{\circ} 40^{\prime} 20^{\prime \prime}$ de latitude Sul, e $34^{\circ} 57^{\prime} 52^{\prime \prime}$ e $37^{\circ} 02^{\prime} 48^{\prime \prime}$ de longitude Oeste de acordo com a Agência Pernambucana de Águas e Clima. Devido à sua conformação alongada no sentido oeste-leste, essa bacia tem posição estratégica no espaço estadual, servindo de grande calha hídrica de ligação entre a Região Metropolitana do Recife e a região do Sertão do Estado. Os trechos superior, médio e submédio da bacia estão localizados nas regiões do Sertão (pequena porção) e Agreste do Estado, enquanto que o trecho inferior tem a maior parte de sua área situada na zona da Mata Pernambucana, incluindo a faixa litorânea do Estado. Limita-se ao norte com a bacia do rio Capibaribe, grupo de bacias de pequenos rios litorâneos e com o Estado da Paraíba, ao sul com a bacia do rio Sirinhaém, a leste, Oceano Atlântico e a oeste com as bacias dos rios Ipanema e Moxotó e o Estado da Paraíba (Figura 1)

Figura 1. Bacia hidrografia do Rio Ipojuca e Municípios de entorno

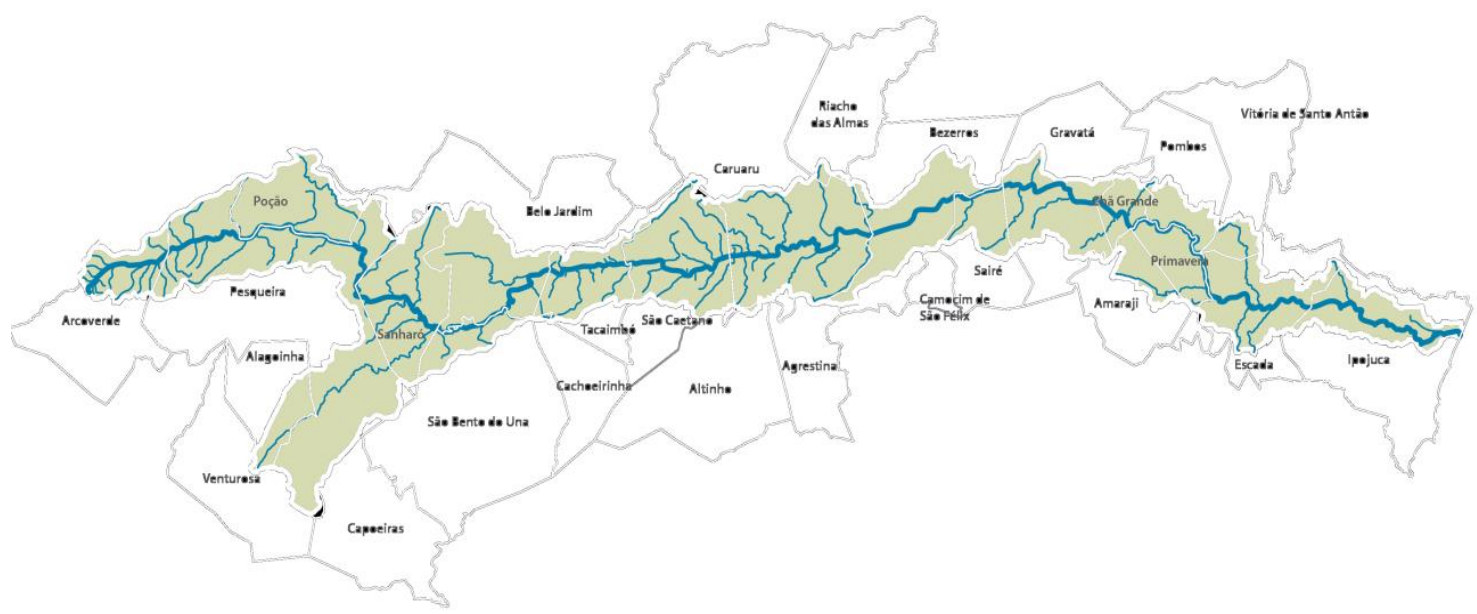

Fonte: Adaptada Autor (2019). 


\subsection{Dados Utilizados e Análise Climática}

A quadra chuvosa na BHRI tem início em fevereiro com chuvas de pré-estação e término acontecendo no mês de agosto. O trimestre chuvoso compreende os meses de maio a julho e os meses secos entre outubro e dezembro. Os fatores causadores de chuvas na área da BHRI e seu entorno são: Zona de Convergência Intertropical, desenvolvimento dos vórtices ciclônicos de altos níveis (VCAS), influência dos ventos alísios de nordeste na condução de vapor e umidade, desenvolvimentos das linhas de instabilidades, orografia e suas apoios locais e regionais formando nuvens e ocasionando chuvas de moderada a forte (Medeiros, 2018).

O estudo foi realizado através do levantamento dos dados de pluviometria, balanço hídrico e dos recursos hídricos superficiais e subterrâneos da área da bacia hidrográfica do rio Ipojuca para os 25 municípios de sua área de entorno. Para a caracterização climática, utilizaram-se os seguintes dados meteorológicos: precipitação, temperatura máxima, média, mínima, amplitude térmica, umidade relativa, insolação do período de 1962 a 2018. A evaporação e evapotranspiração foram calculadas pelos métodos de Thornthwaite (1948) e Thornthwaite e Mather (1955) utilizando programa em planilha eletrônica desenvolvida por Medeiros (2016). Os dados de precipitações foram cedidos pela Superintendência do Desenvolvimento do Nordeste (SUDENE) (1990) e pela Agência Pernambucana de Água e Clima (APAC) (2019).

Utilizaram-se valores da temperatura máxima, média e mínima do ar estimadas pelo software Estima_T (Cavalcanti \& Silva, 1994; Cavalcanti, Silva, \& Sousa, 2006). O Estima_T é um software para fazer estimativas de temperaturas do ar na Região do NEB. Determinaram-se os coeficientes da função quadrática para as temperaturas máxima, média e mínima mensal em função das coordenadas locais: longitude, latitude e altitude, Cavalcanti, Silva e Sousa (2006), dada por:

$$
\mathrm{T}=\mathrm{C}_{0}+\mathrm{C}_{1} \lambda+\mathrm{C}_{2} \varnothing+\mathrm{C}_{3} \mathrm{~h}+\mathrm{C}_{4} \lambda^{2}+\mathrm{C}_{5} \emptyset^{2}+\mathrm{C}_{6} \mathrm{~h}^{2}+\mathrm{C}_{7} \lambda \varnothing+\mathrm{C}_{8} \lambda \mathrm{h}+\mathrm{C}_{9} \varnothing \mathrm{h}
$$

Em que:

$\mathrm{C}_{0}, \mathrm{C}_{1}, \ldots ., \mathrm{C}_{9}$ são as constantes;

$\lambda, \lambda^{2}, \lambda \varnothing, \lambda \mathrm{h}$ longitude;

$\varnothing, \varnothing^{2}, \lambda \varnothing$ latitude;

$\mathrm{h}, \mathrm{h}^{2}, \lambda \mathrm{h}, \varnothing \mathrm{h}$ altura. 
Também estimaram a série temporal de temperatura, adicionando a esta a anomalia de temperatura do Oceano Atlântico Tropical (Silva, Sousa, Cavalcanti, Souza, \& Silva 2006).

$$
\mathrm{T}_{\mathrm{ij}}=\mathrm{T}_{\mathrm{i}}+\mathrm{AAT}_{\mathrm{ij}} \quad \mathrm{i}=1,2,3, \ldots, 12 \quad \mathrm{j}=1950,1951,1952, \ldots .2015
$$

Em que:

$\mathrm{i}=1,2,3, \ldots, 12$;

$\mathrm{j}=1950,1951,1952,1953, \ldots, 2015$.

A qualidade dos dados meteorológicos foi examinada verificando-se todos os dados e os valores que apresentaram grande discrepância, quando comparados aos observados na própria série da estação. Para tanto, utilizaram de análise, no tocante à sua consistência, de homogeneização e no preenchimento de falhas em cada série. No caso de problemas nos equipamentos ou por impedimento do observador que resultaram em dias sem observação ou mesmo intervalo de tempos maiores, os dados falhos foram preenchidos com os dados de três postos vizinhos, localizados o mais próximo possível, onde se aplicou da seguinte forma:

$$
P x=\frac{1}{3}\left(\frac{N x}{N a} P a+\frac{N x}{N b} P b+\frac{N x}{N c} P c\right)
$$

Em que:

Px é o valor de chuva que se deseja determinar;

Nx é a precipitação diária do posto $\mathrm{x}$;

NA, NB e NC são, respectivamente, as precipitações diárias observadas dos postos vizinhos A, $\mathrm{B}$ e $\mathrm{C}$;

PA, PB e PC são, respectivamente, as precipitações observadas no instante que o posto $\mathrm{x}$ falhou.

\section{RESULTADOS E DISCUSSÃO}

A Figura 2 demonstra as flutuações mensais pluviais médias históricas, máxima e mínima absolutas correspondente aos 25 municípios do entorno da bacia hidrográfica do Rio Ipojuca (BHRI). Entre abril a agosto registram-se os picos de altas incidências pluviométricas, sendo junho o mês mais chuvoso. Entre os meses de outubro a janeiro registram-se as menores incidências pluviométricas.

As precipitações mínimas absolutas foram registradas no município de Caruaru com 9,5 $\mathrm{mm}$ e 5,8 mm, respectivamente, entre os meses de outubro e novembro. A precipitação máxima 
absoluta ocorreu entre os meses de abril e julho, oscilando entre 225,5 mm e 320,2 $\mathrm{mm}$ no município de Ipojuca. Estudos como o do Intergovernmental Panel on Climate Change [IPCC], (2014), IPCC, (2007), Tammets e Jaagus (2013), Medeiros, Borges e Vieira (2012) corroboram os resultados encontrados e debatidos no presente trabalho

Figura 2. Precipitação média histórica, máximas e mínimas absolutas ( $\mathrm{mm}$ ) para a área da bacia hidrográfica do rio Ipojuca para o período de 1962-2018.

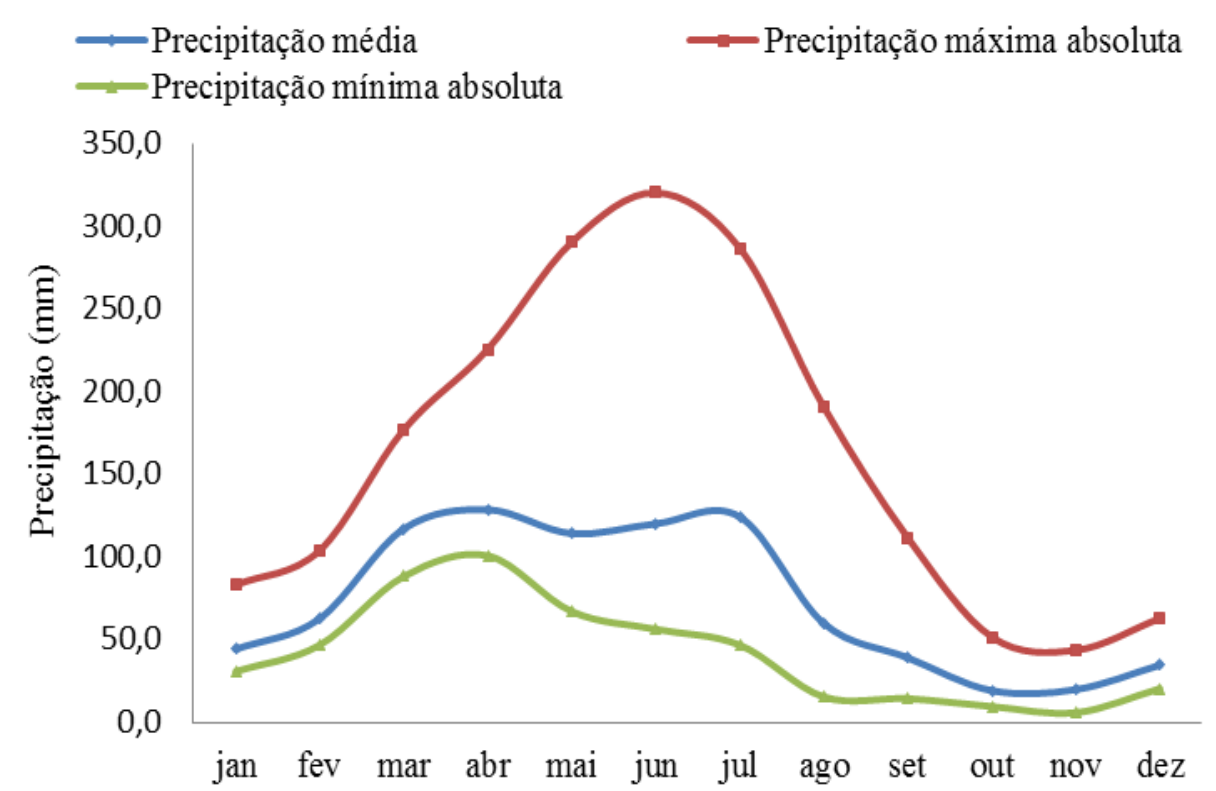

Fonte: Medeiros, (2020).

As condições climáticas pluviais da área da BHRI apresentam em seu ciclo anual períodos seco e chuvoso, sendo o período seco intercalado por período de chuvas de curta intensidade e irregular. A estação seca, em geral, estende-se por cerca de seis meses do ano em períodos normais, ou às vezes mais longos em períodos de estiagem. O período chuvoso iniciase em abril e pode estender-se até início de agosto.

A Figura 3 destaca as flutuações das temperaturas máxima, média e mínima absolutas do ar $\left({ }^{\circ} \mathrm{C}\right)$ para a área da BHRI. Observou-se que a temperatura média anual foi de $22,8^{\circ} \mathrm{C}$ e suas flutuações mensais oscilando entre $20,4^{\circ} \mathrm{C}$ (julho) a $24,5^{\circ} \mathrm{C}$ em janeiro (Figura 3). Entre dezembro a março, a flutuação da temperatura média variou de $24,1^{\circ} \mathrm{C}$ a $24,5^{\circ} \mathrm{C}$ e entre julho e agosto, de $20,4{ }^{\circ} \mathrm{C}$ e $20,5^{\circ} \mathrm{C}$. As temperaturas máxima e a mínima absolutas registradas foram de $27,1^{\circ} \mathrm{C}$ no mês de fevereiro no município de Ipojuca e de $18,1^{\circ} \mathrm{C}$ no mês de julho no 
município de Poção. Estudos como os de Marengo, Schaffer, Zee, \& Pinto (2015), Marengo \& Camargo, (2007), Medeiros, Holanda, \& França (2018) corroboram com os nossos resultados apresentados.

Macedo (2012) estudando as flutuações hidrotérmicas em duas bacias hidrográficas no município de Jataí-GO mostrou que as diferenças de altitude entre os pontos de coleta foram maiores que $100 \mathrm{~m}$, e que esta variação não foi decisiva no registro dos valores máximos e mínimos de temperatura. $\mathrm{O}$ autor afirma que outros fatores, como as formas de uso do solo e a exposição das vertentes, contribuem nas variações da temperatura.

Figura 3. Temperatura máxima, média e mínima absoluta do ar $\left({ }^{\circ} \mathrm{C}\right)$, para a área da BHRI.

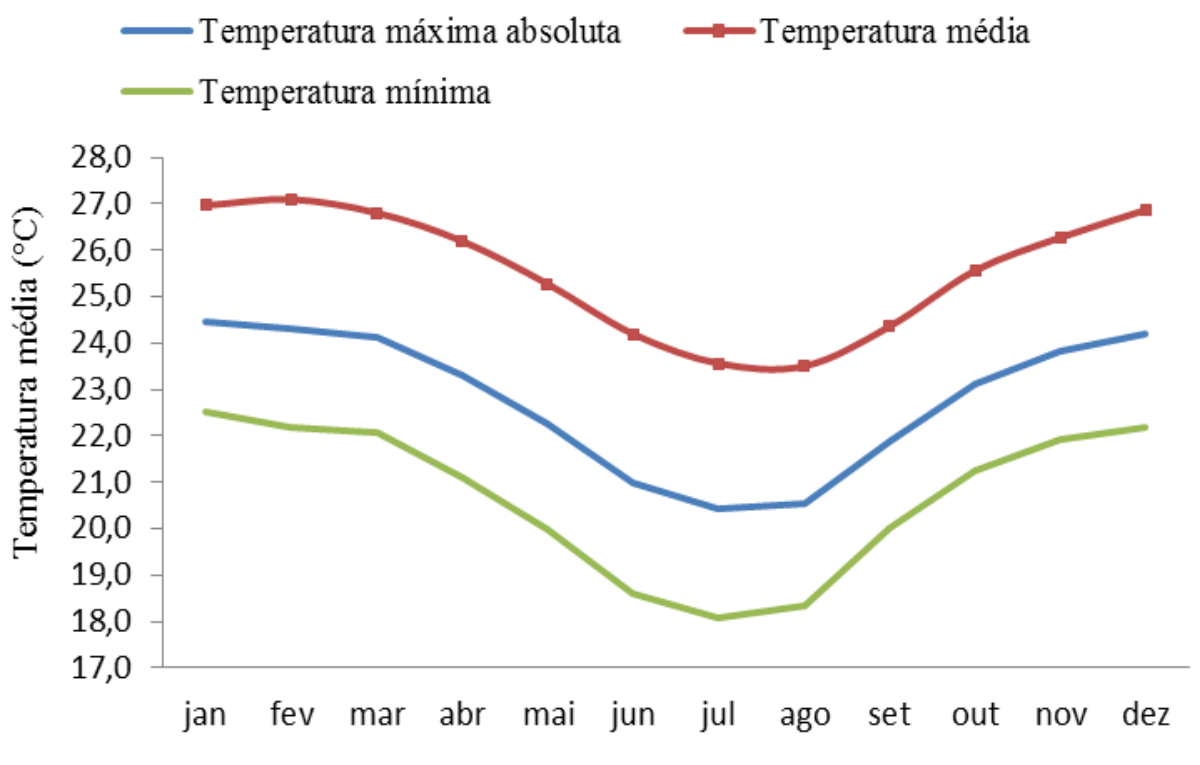

Fonte: Medeiros, (2020).

A Figura 4 apresenta os resultados de insolações máxima, média e mínima absoluta (hora e décimo) para a área BHRI. Os dados a respeito de insolação vêm sendo ponderados com amplo interesse quanto a seus efeitos e suas aplicações adversas sobre plantas, animais e nos seres humanos, causados pela radiação ultravioleta em função da redução da camada de ozônio (Barrett e Curtis1992).

Os índices de insolação são necessários para o incremento de estudos aplicados na Agrometeorológia, Engenharia Agrícola entre tantas outras aplicabilidades, cujo objetivo busca obter uma melhor integração dos cultivos agrícolas aos recursos climáticos. Mais 
particularmente, o seu efeito sobre o comportamento do desenvolvimento vegetal, no que se refere à fotossíntese, evapotranspiração, fisiologia de plantas e desenvolvimento de pragas e doenças. Estudos como os de Medeiros (2018) e Medeiros, Holanda, \& França (2018) corroboram com os resultados em debate neste estudo..

Figura 4. Insolação máxima, média e mínima absoluta (hora e décimo) para a área BHRI.

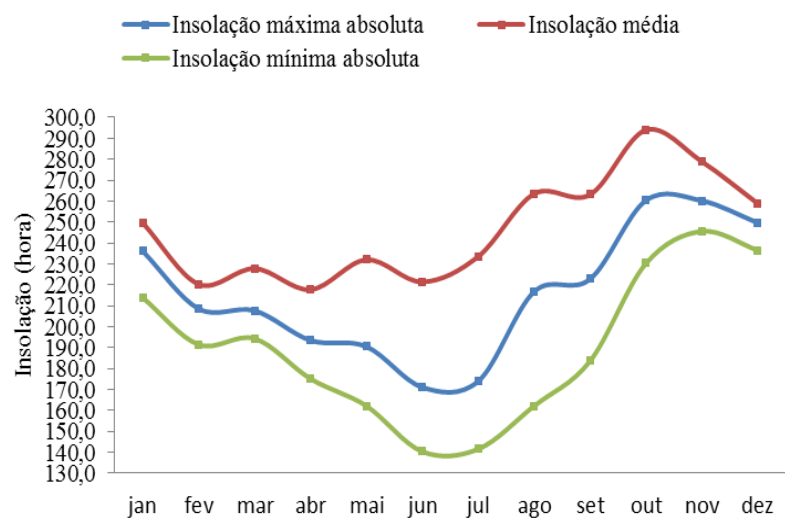

Fonte: Medeiros (2020).

Devido à sua posição geográfica, os raios solares incidem quase diretamente sobre a bacia hidrográfica da área de estudo durante todo o ano. A quantidade mínima de insolação que atinge a superfície do solo apresenta valores médios mensais oscilando entre 171 a 260,3 horas/mês. O mês de junho (171 hora/mês) é o de baixa insolação e o mês de outubro (260,3 hora/mês) é o de alta insolação. A insolação média anual na BHRI é de 2.590,8 horas e o município de Ipojuca tem a maior incidência de insolação (2.860,6 horas) e o de Tacaimbó registra a menor incidência com $2.289,7$ horas.

A umidade relativa do ar (UR) média mensal oscila ao longo do ano em conformidade com a cobertura da nebulosidade e do regime de chuvas da área em estudo. Na Figura 5 podese observar as variabilidades da UR máxima, média e mínima absoluta. O trimestre úmido ocorre nos meses de maio, junho e julho com flutuação em torno de 76,4\% a 76,8\%. O trimestre de baixa umidade relativa ocorre entre os meses de setembro e novembro e fluem entre 59,6\% a $66,1 \%$, com umidade relativa do ar anual de 69,5\% (Figura 5). A umidade relativa máxima absoluta oscila entre $74 \%$ a 91,6\% e a mínima absoluta flui entre $40 \%$ a 67\%. Os resultados dos trabalhos de Holanda, Medeiros, França e Ferraz (2019); Melo, Medeiros e Sousa (2015) e Medeiros, Sousa e Gomes (2014) assemelham-se aos obtidos e discutidos no presente trabalho. 
Figura 5. Umidade relativa máxima, média e mínima absoluta do ar $\left({ }^{\%}\right)$, para a área da BHRI.

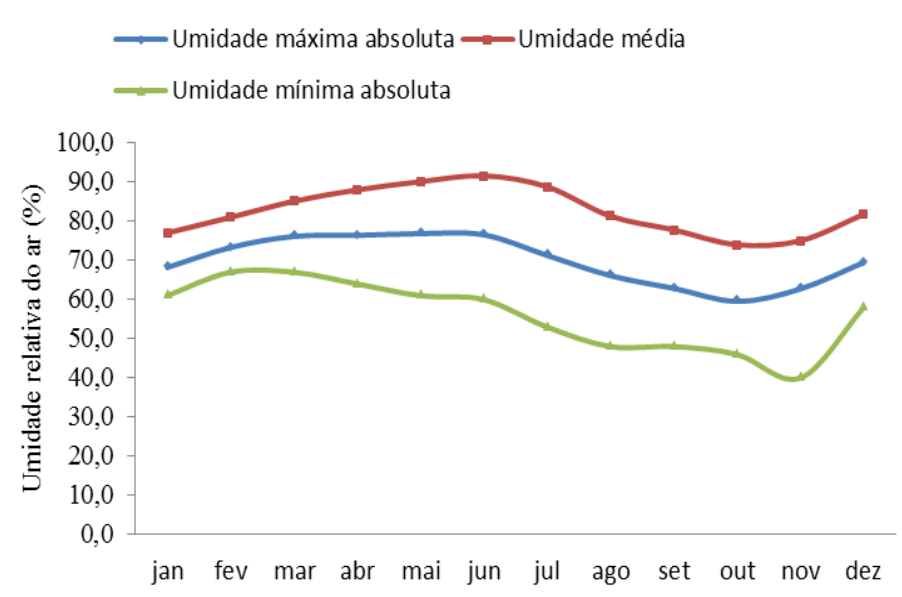

Fonte: Medeiros, (2020).

A evapotranspiração (ETP) é um importante parâmetro para se pautar a dinâmica da atmosfera ou o clima do Nordeste, visto que nessas regiões, a taxa evaporimétrica é alta, acarretando adaptações do solo e da cobertura vegetal (Silva, 1977). As flutuações das temperaturas na área estudada são elevadas, a umidade relativa do ar é baixa e os índices pluviais são inferiores a ETP, caracterizando uma acentuada deficiência hídrica. O estudo de Andrade e Medeiros (2005) corroboram com os resultados aqui discutidos.

A ETP e a evaporação (EVR) (Figura 6) igualam-se entre os meses de março a julho, apresentam o máximo evaporativo entre os meses de agosto a janeiro e os meses de agosto a dezembro como de baixos meses evaporativos.

Figuras 6. Evapotranspiração e evaporação média mensal da área da BHRI. 


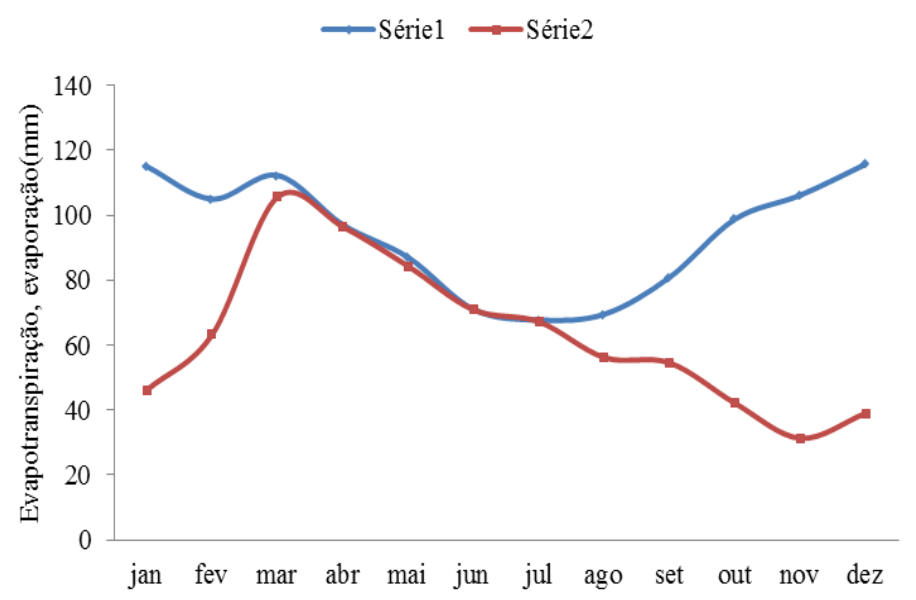

Fonte: Medeiros, (2020).

A evaporação e evapotranspiração foram estimadas a partir da fórmula de Thornthwaite (1948) e Thornthwaite e Mather (1955). A Tabela 1 apresenta a flutuação da evaporação e evapotranspiração mês a mês para a área da BHRI. A ETP mínima ocorre no mês de junho com 67,2 mm e o máximo de ETP ocorre no mês de dezembro com 114,9 mm. A evaporação mínima ocorre no mês de outubro com 35,4 mm e no mês de março evaporam 111,4 mm.

A BHRI tem uma média pluviométrica anual de 882,6 $\mathrm{mm}$ durante 57 anos de observação pluviométrica e a sua evapotranspiração potencial é $1118 \mathrm{~mm}$ A evaporação real segue os índices pluviais, ocorrendo deficiência hídrica entre os meses de setembro a fevereiro e há excedente hídrico de 17,3 mm e $57 \mathrm{~mm}$ nos meses de junho e julho, respectivamente.

Tabela 1. Representação do balanço hídrico climatológico para a área da BHRI entre o período de 1962-2018.

\begin{tabular}{cllllll}
\hline Meses & T $\left({ }^{\circ} \mathrm{C}\right)$ & P $(\mathrm{mm})$ & ETP $(\mathrm{mm})$ & EVR $(\mathrm{mm})$ & DEF $(\mathrm{mm})$ & EXC $(\mathrm{mm})$ \\
\hline Jan & 24,5 & 44,1 & 114,5 & 46,7 & 67,8 & 0,0 \\
Fev & 24,3 & 62,6 & 104,2 & 63,5 & 40,7 & 0,0 \\
Mar & 24,1 & 116,9 & 111,4 & 111,4 & 0,0 & 0,0 \\
Abr & 23,3 & 128,6 & 96,1 & 96,1 & 0,0 & 0,0 \\
Mai & 22,3 & 114,1 & 86,2 & 86,2 & 0,0 & 0,0 \\
Jun & 21,0 & 120,0 & 70,3 & 70,3 & 0,0 & 17,3 \\
Jul & 20,4 & 124,3 & 67,2 & 67,2 & 0,0 & 57,0
\end{tabular}




\begin{tabular}{cllllll} 
Ago & 20,5 & 59,7 & 69,0 & 68,6 & 0,4 & 0,0 \\
Set & 21,9 & 39,0 & 80,7 & 70,0 & 10,6 & 0,0 \\
Out & 23,1 & 19,1 & 98,3 & 52,0 & 46,4 & 0,0 \\
Nov & 23,8 & 19,8 & 105,2 & 35,4 & 69,8 & 0,0 \\
Dez & 24,2 & 34,5 & 114,9 & 40,9 & 74,0 & 0,0 \\
Média & 22,8 & 73,6 & 1118 & 808,2 & 309,7 & 74,4 \\
\hline
\end{tabular}

Fonte: Medeiros, (2020).

A Figura 7 mostra o balanço hídrico climático para a área da bacia hidrográfica do rio Ipojuca. A capacidade de água disponível (CAD) é igual a $100 \mathrm{~mm}$, compreendida no período de 1962-2018. Observa-se que no regime de chuvas anual, com uma estação seca bem definida, associado à má distribuição das chuvas durante a estação chuvosa e à pobreza de nutrientes dos solos, em geral, é necessário um alto nível técnico para a produção agrícola.

Figura 7. Balanço hídrico climático médio para a área da BHRI com ccapacidade de água disponível (CAD) igual a $100 \mathrm{~mm}$.

Deficiência, Excedente, Retirada e Reposição Hídrica ao longo do ano

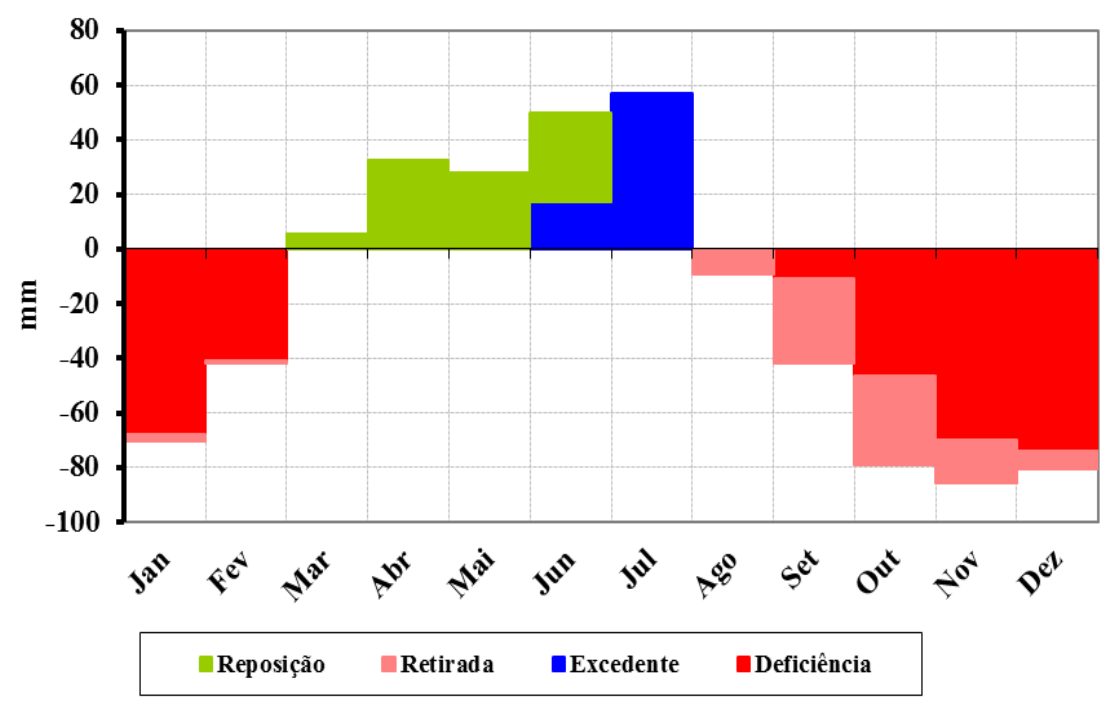

Fonte: Medeiros, (2020).

Foram registradas deficiências hídricas entre os meses de setembro e fevereiro e nos 
meses de junho e julho excedente hídrico. A reposição de água no solo ocorreu entre os meses de março a junho e as retiradas das águas entre os meses de agosto a fevereiro (Figura 7).

\section{CONSIDERAÇÕES FINAIS}

O diagnóstico concretizado neste estudo representa uma aproximação das potencialidades da área da BHRI, em termos de clima, recursos hídricos e das reais necessidades de água para as principais atividades de importância econômica, concebidas através do balanço hídrico.

Os aspectos físicos e as características do uso do solo são os responsáveis pela distribuição das temperaturas, sendo que locais densamente construídos e desprovidos de vegetação apresentaram temperaturas maiores, enquanto que nos locais com maior taxa de arborização e menores taxas de construções foram registradas temperaturas menores.

Parte da variabilidade interanual da insolação está associada à ocorrência dos efeitos locais e regionais e as contribuições da larga e meso escala registradas no estudo.

Os municípios de entorno necessitam desenvolver-se pautados em planejamento urbano eficiente que possa suportar fenômenos naturais de maior magnitude. Os ambientes instáveis da cidade não deveriam ser ocupados por construções e nem ter sua dinâmica natural alterada.

A intervenção do poder público para a implementação de uma política de gestão das águas e dos recursos hídricos deve ser elaborada com a finalidade de que a população possa desfrutar desse recurso de forma sustentável.

\section{REFERÊNCIAS}

Andrade Júnior, A. S., \& Medeiros R. M. (2005). Evapotranspiração de Referência mensal para o Estado do Piauí. Revista Brasileira de Engenharia Agrícola e Ambiental, (1), 560 - 564.

Amorim, R. C. F., Amorim, D. K. F., Leite, C. C., \& Gomes, H. B. (2004). Análise climática para a cidade de Curitiba/PR. Anais do Congresso Brasileiro de Meteorologia, Fortaleza, CE, Brasil, 13.

Artaxo, P. (2014). Uma nova era geológica em nosso planeta: Antropoceno? Revista USP, 103, 13-24. Recuperado de http://www.revistas.usp.br/revusp/article/view/99279. doi: https://doi.org/10.11606/issn.2316-9036.v0i103p13-24 
Barrett, E. C., \& Curtis, L. F. (1992). Introduction to environmental Remote Sensing (3rd. ed. 425 p.). London: Chapman \& Hall.

Camargo, A. P. (1971). Balanço hídrico no Estado de São Paulo (Boletim Técnico, 116).

Campinas: IAC.

Cavalcanti, E. P., Silva, V. P. R., \& Sousa, F. A. S. (2006). Programa computacional para a estimativa da temperatura do ar para a região Nordeste do Brasil. Revista Brasileira de Engenharia Agrícola e Ambiental, 10(1), 140-147.

Cavalcanti, E. P., \& Silva, E. D. V. (1994). Estimativa da temperatura do ar em função das coordenadas locais. Anais do Congresso Brasileiro de Meteorologia, Belo Horizonte, MG, Brasil, 8.

Holanda, R. M., Medeiros, R. M., França, M. V., \& Ferraz, J. X. V. (2019). Oscilações da temperatura e umidade relativa do ar em Recife - PE. In Terra - Habitats Urbanos e Rurais (1a ed., v.2, pp. 2513-2523). Ituiutaba, MG: Barlavento.

Horikshi, A. S., \& Fisch, G. (2007). Balanço hídrico atual e simulações para cenários climáticos futuros no Município de Taubaté, SP, Brasil. Revista Ambiente e Água - An Interdisciplinary Journal of Applied Science, 2(2), 33-46. Recuperado de http://www.ambi-agua.net/seer/index.php/ambi-agua/article/view/55

Intergovernmental Panel on Climate Change. (2014). Climate change 2014: impacts, adaptation, and vulnerability: part B: regional aspects - Working Group II Contribution to the Fifth Assessment Report of the Intergovernmental Panel on Climate Change. New York: Cambridge University Press. Recuperado de https://www.ipcc.ch/report/ar5/wg2/.

Intergovernmental Panel on Climate Change (2007). The physical science basis, contribution of Working Group I to the Fourth Assessment Report of the Intergovernmental Panel on Climate Change. Cambridge: Cambridge University Press.

Klering, E. V., Custódio, M. S., Fontana, D. C., \& Berlato, M. A. (2007). Relação entre os perfis temporais de NDVI/MODIS da cultura do arroz irrigado, a insolação e o rendimento na região da Campanha do Rio Grande do Sul. Anais do Simpósio Brasileiro de Sensoriamento Remoto, Florianópolis,SC, Brasil, 13.

Lima, F. B., \& Santos, G. O. (2009). Balanço hídrico-espacial da cultura para o uso e ocupação atual da bacia hidrográfica do Ribeirão Santa Rita, Noroeste do Estado de São Paulo (Trabalho de conclusão de curso). Fundação Educacional de Fernandópolis, Fernandópolis, SP, Brasil. 
Macedo, E. A. G. (2012). Variações higrotérmicas: o caso das bacias do Açude (sapo) e Capoeira em Jataí-GO (Dissertação mestrado). Universidade Federal de Goiás, Jataí, GO, Brasil.

Magalhães, G. B., Zanella, M., \& Sales, M. C. L. (2009). A ocorrência de chuvas e a incidência de leptospirose em Fortaleza - CE. Hygeia, Revista Brasileira de Geografia Médica e da Saúde, 5(9), 77-87. $\quad$ Recuperado de http://www.seer.ufu.br/index.php/hygeia/issue/view/787

Marengo, J. A., Schaeffer, R., Zee, D., \& Pinto, H. S. (2015). Mudanças climáticas e eventos extremos no Brasil. Rio de Janeiro: FBDS. Recuperado de http://www.fbds.org.br/cop15/FBDS_Mudancas Climaticas.pdf.

Marengo, J. A., \& Camargo, C G. 2007. Trends in Extreme air temperatures in Southern Brazil. International Journal Climatology, 28, 893-904.

Medeiros, R. M. (2018a). Insolação decadal para o Município Recife - PE, Brasil. Revista Geográfica Acadêmica. 12, 124 - 137.

Medeiros, R. M.; Holanda, R. M., \& Franca, M. V. (2018). Interpolação da insolação média para o estado do Piauí - Brasil. Revista de Geografia (Recife). 35, 170 - 189.

Medeiros, R. M.; Kozmhinsky, M.; Holanda, R. M., \& Silva, V. P. (2018).Temperatura média do ar e suas flutuações no Estado de Pernambuco, Brasil. Revista Brasileira de Meio Ambiente, 2(1), 81-93.

Medeiros, R. M. (2016a). Fatores provocadores elou inibidores de chuva no estado de Pernambuco.

Medeiros, R. M. (2016b). Programa do balanço hídrico segundo o método do balanço hídrico de Thornthwaite e Mather.

Medeiros, R. M., Sousa, F. A. S., \& Gomes Filho, M. F. (2014). Variabilidade da umidade relativa do ar e da temperatura máxima na bacia hidrográfica do rio Uruçuí Preto. Educação Agrícola Superior, (28)136 - 141.

Medeiros, R. M., Borges, C. K., \& Vieira, L. J. S. (2012). Análise climatológica da precipitação no município de Cabaceiras - PB, no período de 1930-2011 como contribuição a Agroindústria In: Seminário Nacional da Agroindústria. Jornada Nacional da Agroindústria, Cabaceiras, PB, Brasil, 5.

Melo, V. S., Medeiros, R. M, \& Sousa, F. A. S. (2015, setembro). Variação média mensal e anual da umidade relativa do ar para 11 municípios no estado de Pernambuco, Brasil. Anais do Congresso Técnico Científico de Engenharia e da Agronomia, Fortaleza, CE, Brasil. 
Nobre, P., \& Melo, A. B. C. (2001, dezembro). Variabilidade climática intra-sazonal sobre o Nordeste do Brasil em 1998 - 2000. Revista Climanálise.

Paula, R. K., Brito, J. I. B., \& Braga, C. C. (2010). Utilização da análise de componentes principais para verificação da variabilidade de chuvas em Pernambuco. Anais do Congresso Brasileiro de Meteorologia, Belém, PA, Brasil, 16.

Pereira, A. R., Angelocci, L. R., \& Sentelhas, P. C. (2002). Agrometeorologia: fundamentos e aplicações práticas (478р.). Guaíba: Agropecuária.

SILVA, M. A. V. Evapotranspiração em cultura irrigada no semi-árido sub-médio São Francisco. INPE, 1977.

Silva, V. P. R, Pereira, E. R. R, Azevedo, P. V, Sousa, F. A. S., \& Sousa, I. F. (2011). Análise da pluviometria e dias chuvosos na região Nordeste do Brasil. Revista Brasileira de Engenharia Agrícola e Ambiental, 15(2), 131-138.

Silva, V. P. R., Sousa, F. A. S., Cavalcanti, E. P., Souza, E. P., \& Silva, B. B. (2006). Teleconnections between sea-surface temperature anomalies and air temperature in northeast Brazil. Journal of Atmospheric and Solar-Terrestrial Physics, 68(1), 781-792.

Simioni, J. P. D., Rovani, F. F. M, Iensse, A. C., \& Wollmann, C. A. (2014). Caracterização da Precipitação Pluviométrica na Microbacia Hidrográfica do Rio Ibicuí, RS. Revista do Departamento de Geografia - USP, 28, 112-133.

Souza, J. D., Silva, B. B., \& Ceballos, J. C. (2008). Estimativa da radiação solar global à superfície usando um modelo estocástico: caso sem nuvens. Revista Brasileira de Geofísica, 26, 31- 44.

Tammets, T., \& Jaagus, J. (2013). Climatology of precipitation extremes in Estonia using the method of moving precipitation totals. Theoretical and Applied Climatology, 111(3-4), 623-639.

Thornthwaite, C. W. (1948). An approach toward a rational classification of climate. Geogr. Rev, 38, 55-94.

Thornthwaite, C. W., \& Mather, J. R. (1955). The water balance: publications in climatology (104 p.). New Jersey: Drexel Institute Of Technology 